\title{
Capítulo 5 Agua y salud en México: patógenos y legislación
}

\section{Chapter 5 Water and health in Mexico: pathogens and legislation}

BARRERA-BERNAL, Clementina†, DOMÍNGUEZ-BARRERA, Clemen y GUZMÁN-GUILLERMO, Jorge

Facultad de Biología Xalapa, Universidad Veracruzana

División de Estudios de Posgrado, Facultad de Medicina, Universidad Nacional Autonoma de México

ID 1 ${ }^{\mathrm{er}}$ Autor: Clementina, Barrera-Bernal / ORC ID: 0000-0003-0865-8360

ID $1^{\mathrm{er}}$ Coautor: Clemen, Domínguez-Barrera / ORC ID: 0000-0001-6788-7759

ID $2^{\text {do }}$ Coautor: Jorge, Guzmán-Guillermo / ORC ID: 0000-0003-2137-3028

DOI: $10.35429 /$ H.2020.9.62.76 


\title{
Resumen
}

Se resume el panorama en México sobre las enfermedades infecciosas y no infecciosas transmitidas por el agua, su etiología y sintomatología. Además, se presenta un análisis sobre la legislación mexicana en este tema. Finalmente, se abordan otros nuevos temas poco tratados en la literatura pero con una importancia primaria como son las enfermedades emergentes transmitidas por el agua, vertido de antibióticos en el agua de drenaje y el efecto del cambio climático en la salud humana.

\section{Enfermedades emergentes, Bacterias, Virus}

\begin{abstract}
In this chapter we resume the panorama about infectious or no infectious waterborne diseases in Mexico, its etiology and symptomatology. Furthermore, an analysis about mexican legislation in this topic is presented. Finally, we explain other new topics little treated but of primary importance such as emerging waterborne diseases, antibiotics in drain water and the effect of climate change on human health.
\end{abstract}

\section{Emerging diseases, Bacteria, Viruses}

\section{Introducción}

Las enfermedades transmitidas por el agua nos han acompañado como especie humana desde nuestros orígenes evolutivos, debido a nuestra necesidad fisiológica de consumirla. Sin embargo, el agua se encuentra muchas veces contaminada por diversas partículas como bacterias, protozoarios, hongos, virus e incluso compuestos o iones inorgánicos, que pueden tener un efecto tanto negativo como positivo sobre nuestra salud. Si bien la mayor parte de los contaminantes del agua son inocuos para nuestra fisiología, ocasionalmente algunos organismos o compuestos químicos logran atravesar nuestras barreras mucosas y causar enfermedades leves o mortales.

Es por ello que en este capítulo presentamos una revisión bibliográfica del tema de las enfermedades transmitidas por el agua, como una puesta al día de las enfermedades más recurrentes, su etiología y sintomatología. Por otro lado se presenta un panorama general de la legislación en México que regula la sanidad en el agua para el consumo humano y lo relacionado con sus usos. Además, se retoman temas novedosos como las enfermedades emergentes cuyo número de infecciones en humanos ha aumentado en los últimos años. Asimismo, se tratan otros temas de interés público como la disposición inadecuada de antibióticos y los efectos que ello a traído consigo en la aparición de cepas bacterianas multirresistentes. Finalmente, se hace un trata el efecto que tendría el cambio climático sobre las enfermedades trasmitidas por el agua y por consecuencia en la salud humana.

\subsection{Patógenos trasmitidos por el agua en la historia}

Como en muchas otras áreas del conocimiento científico, durante la edad media los avances de las tecnologías relacionadas a la purificación, extracción y distribución del agua fueron mínimos, debido a que la experimentación científica era escasa (Mays, 2013). Afortunadamente, en épocas anteriores se produjeron avances que sentaron las bases para las tecnologías modernas del agua. Los escritos más antiguos relacionados a la purificación del agua son tratados médicos en Sánscrito escritos alrededor del 2000 a.c., ¡hace más de 4000 años! En ese tratado exponen que "es bueno mantener en agua en vasijas de cobre, exponerla al sol y luego filtrar con carbón de leña" (Place, 1905 en Mays, 2013). Lo cual no parece tan desacertado si lo extrapolamos a estudios recientes. Se ha concluido que al mantener el agua en contenedores de cobre se limita el crecimiento de algunas bacterias patógenas y se genera también un efecto bactericida sobre Shigella flexneri, Salmonella enterica Typi, Salmonella Paratyphy, Vibrio cholerae $\mathrm{O} 1$ y algunas cepas patogénicas de Escherichia coli (Preethi et al., 2012). Esto último resulta interesante pues los desordenes gastrointestinales más comunes en la actualidad son causados por esos agentes etiológicos.

En la cultura Griega, 1500 años después, Hipócrates parece haber dilucidado una relación entre la pureza del agua y la salud del ser humano, ya que a sus pacientes les hacia beber agua limpia y también curaba sus heridas con agua limpia o con vino (Andrades et al., 2004). 
Así, a Hipócrates, se le atribuye la fabricación de un artefacto (Hippocrate's sleeve) capaz de limpiar las partículas suspendidas en el agua, posteriormente eliminaba los patógenos al ser hervida, lo cual cobra importancia al conocerse que lo daba a sus pacientes para que estos tuvieran acceso a agua limpia y acelerar su recuperación (Lauria, 2008).

Para las culturas mesoamericanas, la abundancia y manejo del recurso agua en los ecosistemas presentes en esa región marcó un aspecto decisivo en su florecimiento, majestuosidad y desarrollo (Scarborough y Gallopin, 1991). Numerosas deidades, ceremonias y expresiones artísticas nos relatan la importancia que tenía el agua para estas culturas. En el México prehispánico florecieron culturas cuyo esplendor y modernidad, no se logró en otras zonas del mundo. Parte del éxito y poder de los aztecas fue el correcto manejo que le dieron a su recurso agua, la cual la almacenaban, purificaban, distribuían y veneraban a través de distintas deidades como Tláloc, Chalchiutlicue y Huitzilopochtli. Asimismo, se sabe que la población que habitaba la gran Tenochtitlán se bañaba varias veces al día y fabricaba jabones, desodorantes y pastas dentales como parte de sus medidas de higiene. También se sabe usaban el agua para limpiar las calles y había empleados públicos encargados de llevar a cabo las actividades de limpieza de los espacios públicos (Becerril y Jiménez, 2007). Fue así que hasta la llegada de los españoles y la caída de estos sistemas de manejo del agua es como la ciudad de Temochtital y la cultura Azteca es doblegada. Es por ello, que se habla de una guerra biológica indirecta más que una de una conquista de guerra cuerpo-cuerpo, ya que muchos patógenos eran desconocidos para los aztecas y por consiguiente no contaban con anticuerpos frente a estos.

\subsection{Agua y salud en el México moderno}

Uno de los problemas actuales que poca relación tiene con los patógenos es la ausencia del consumo de agua entre la población mexicana. Pareciera que uno de los países con mayor cantidad de agua disponible tendría una población con acceso al recurso en cantidades suficientes y en una calidad excelente. Sin embargo, esto no sucede así. Para el año 2007 se reporta que en México aún mueren 4800 personas por complicaciones derivadas de la diarrea y solo un $74 \%$ de la población tiene acceso a servicios de saneamiento (Llorente y Casas, 2007).

Del otro lado de la moneda, una población poco estudiada y atendida en el país por programas de salud es aquella que aunque tenga acceso al recurso no toma "agua simple" y prefiere el consumo de refrescos. En México, el consumo de refrescos (bebidas azucaradas) y otras conductas alimenticias junto con el sedentarismo ubican al país con el mayor índice de obesidad del mundo (Espinosa-Montero et al., 2013). Y más que las enfermedades ocasionadas por patógenos trasmitidos por el agua, las afecciones cardiacas y metabólicas como la hipertensión y la diabetes, provocan la mayor cantidad de muertes e incapacidades entre la población del país (Rivera et al., 2008). Es por ello que recientemente se han puesto en marcha programas que tratan de incrementar el consumo de agua entre escolares (Carriedo $e t$ al., 2013; Elder et al., 2014). Si bien son esfuerzos puntuales, sirven de referencia y punto de partida de un problema de salud en relación al agua que urge ser atendido. Estudios como el de Arreguín-Moreno et al. (2009), relacionan la preferencia por el consumo de agua simple versus las bebidas azucaradas con el grado de estudios de la población, y encuentran que los mexicanos con un alto nivel de estudios prefieren más tomar agua simple y quienes tienen un nivel de estudios bajo elijen las bebidas azucaradas.

\subsection{Patógenos trasmitidos por el agua.}

Las tecnologías relacionadas con la extracción, distribución y consumo de agua han mejorado con la evolución misma del hombre. Sin embargo, los avances más significativos han surgido apenas en los últimos dos siglos, con el entendimiento del origen y epidemiología de las enfermedades microbianas. Si bien el color, sabor y olor del agua fueron un primer recurso de discriminación para el consumo del recurso, no fue hasta la postulación de la teoría microbiana de la enfermedad que se entendió que ciertas enfermedades son causadas por agentes biológicos.

El microbioma acuático en aguas naturales es altamente diverso, pues está formado por bacterias, protoctistas, hongos y animales. Aunque la mayoría de estos organismos no son patogénicos, existen organismos capaces de burlar las barreras mucosas y dérmicas del cuerpo humano ocasionando una amplia gama de padecimientos. Estas enfermedades comúnmente están asociadas a desequilibrios gastrointestinales. 
Básicamente son tres grupos de microorganismos patógenos trasmitidos al entrar en contacto con el agua; virus, bacterias y protozoarios (Leclerc et al., 2002). Además, algunos patógenos que si bien no son transmitidos por el agua, como los causantes de la malaria, dengue o la enfermedad de Chagas, presentan vectores que necesitan de un medio acuático para completar sus ciclos de vida, principalmente hacia los trópicos.

\subsection{Virus}

A diferencia de las bacterias que pueden ser más resistentes a las variables medioambientales al formar estructuras de resistencia, los virus pueden ser fácilmente desactivados por cambios en la temperatura, $\mathrm{pH}$, exposición a la radiación luminosa, etc. Pocos son los tipos virus que pueden continuar siendo infectivos por un tiempo prolongado después de salir del cuerpo del hospedero. Uno de estos es el Virus de la Hepatitis tipo A (VHA). Se ha documentado extensamente la permanencia y transmisión de VHA en agua sin tratamientos para su consumo, o bien agua contaminada (Bruguera, 2006; Valdespino et al., 2007). Aunque generalmente los niños adquieren este virus en sus primeros meses de vida y el proceso infeccioso es asintomático, en los países desarrollados y en vías de desarrollo el aumento en las prácticas de sanidad ha llevado a que los individuos se infecten con este virus en etapas posteriores. En los casos en que la infección por VHA es sintomática, puede presentarse en forma de un cuadro ligero de ictericia acompañada de síntomas parecidos a los de la gripa, hasta la falla hepática fulminante y encefalopatía (Rezende et al., 2003). La distribución de VHA está zonificada en el globo, siendo África, Asia y Latinoamérica las regiones con mayor incidencia (Tanno y Fay, 2005). Para México la seroprevalencia de VHA arroja datos crudos, pues se comporta de tal manera que funge como un indicador de inequidad social en la población, para el 2007 el 87\% de la población (78.7 millones de personas) se encontraban infectadas del virus, asimismo Valdespino et al. (2007) argumentan que esto puede deberse a diferencias en las condiciones sanitarias y sociales en el país.

\subsection{Bacterias patógenas transmitidas por el agua}

Las enfermedades bacterianas son las infecciones agudas o crónicas más comunes en la población humana. Las especies y cepas patogénicas comúnmente están relacionadas con aquellas que producen eventos agudos, violentos, contagiosos y si no son tratados; potencialmente mortales. Las enfermedades más comunes ocasionadas por bacterias relacionadas al consumo de agua son: cólera, fiebre tifoidea y otras formas de salmonelosis, disentería bacilar o shigelosis, gastroenteritis o diarreas agudas.

\subsection{Cólera}

Los agentes causales del cólera son las bacterias Vibrio cholerae (serotipos O1 y O139). El género Vibrio incluye microorganismos unicelulares muy pequeños de forma curva, responden negativamente a la tintura de Gram, poseen un solo flagelo polar, son anaerobios facultativos, y la mayoría de las especies son oxidasa-positivo y reducen el nitrato al nitrito (Cabral, 2010).

El periodo de incubación varia ampliamente entre la población, pudiendo ser unas cuantas horas hasta cinco días. El cuadro puede ser leve, moderado o grave. Su principal síntoma es la diarrea, que puede estar acompañado por cólico intenso, vómito, hipotermia, fiebre, convulsiones, alteración de la conciencia, pulso débil, insuficiencia renal, entre otros (González et al., 2011). La toxina del cólera es una exotoxina que se une al revestimiento de los intestinos y activa a la adenilciclasa, lo que causa la salida del agua de las células de la mucosa y con ello se arrastran iones de sodio, potasio, cloro y carbohidratos lo que ocasiona la diarrea masiva (Cabral, 2010).

No se sabe con exactitud la ruta de entrada del cólera a México, se cree que llegó por diferentes puntos del territorio (Tampico y Yucatán), probablemente proveniente de Nueva Orleáns, Estados Unidos de América, y se desplazó hasta la Ciudad de México en el año 1833, el cual se conoce como el año del cólera. En esa epidemia se registraron aproximadamente catorce mil muertes. En ese mismo siglo se repitieron varios brotes durante los años de 1850, 1854, 1866 y 1883 (Martinez, 1992; Jiménez-Corona et al., 1995; Tovar y Bustamante, 2000). 


\subsection{Cepas patogénicas de Escherichia coli}

La bacteria Escherichia coli, es comúnmente encontrada en el ambiente y en la microflora de mamíferos, entre ellos el ser humano. Sin embargo, por procesos poco conocidos se han generado y expandido algunas cepas de esta especie que pueden ocasionar enfermedad en las personas. Según Cabral (2010), las cepas de E. coli de importancia clínica que pueden ser trasmitidas por el agua son: $E$. coli enterotoxigénica (llamada O148), E. coli enterohemorrágica (llamada O157:H7) y E. coli enteroinvasiva (llamada O124).

\subsection{Salmonelosis}

Las salmonelosis incluyen una amplia gama de padecimientos y tienen en común ser causadas por bacterias del género Salmonella spp., de la cual existen más de 2500 serotipos. Pero los comúnmente aislados en México son: Thyphimurium, Enteritidis, Derby, Agona y Anatum (Hernández et al., 2011). En contenedores de agua se ha demostrado que la bacteria puede sobrevivir varias semanas cuando las condiciones de temperatura y $\mathrm{pH}$ son favorables (Cabral, 2010).

La patología causada por Salmonella spp., incluye la invasión primaria de los intestinos y localizarse causando trastornos gastrointestinales, o expandirse a otros órganos causando bacteriemia y meningitis en lactantes, o albergarse en huesos. Desafortunadamente, en México se desconocen muchos aspectos epidemiológicos de la enfermedad pero se sabe que al año se reportan alrededor de 15,000 casos de fiebre tifoidea (Mussaret et al., 2006).

\subsection{Shigelosis}

La shigelosis es una enfermedad endémica de climas tropicales y templados. En México la especie más frecuentemente aislada es Shigella flexneri, pero otras especies como S. dysenteriae, S. boydii y S. sonnei pueden causar patogenia. Son bacterias Gram negativas que no presentan motilidad, no fermentan azúcares, son negativas para la oxidasa y positivas para la catalasa. El proceso infeccioso sintomático comienza con dolor abdominal que progresa algunas horas después a diarrea que puede incluir heces con sangre y pus, esto último debido a que las bacterias de Shigella sp. causan ulceración en la mucosa del intestino. Este patógeno es responsable del $11 \%$ de las enteropatías. La enfermedad es importante ya que en menores de 10 años puede causar el Síndrome Urémico Hemolítico, el cual representa una de las causas más frecuentes de falla renal (Mussaret et al., 2006).

\subsection{Patógenos bacterianos emergentes que pueden ser trasmitidos por el agua}

El surgimiento de nuevos patógenos ha sido a la par con la búsqueda de nuevas formas de entretenimiento y selección de alimentos, el surgimiento de una población cada vez más longeva, y una cada vez más común población inmunocomprometida por terapias contra distintos tipos de cánceres, trasplantes de órganos o por ser portadores del virus de la inmunodeficiencia humana (VIH). Esta población inmunocomprometida, ecológicamente ha creado un nicho para algunas bacterias que comúnmente se encuentran en el ambiente.

De estos patógenos emergentes destaca el complejo Mycobacterium avium, relacionado a desordenes en el tracto respiratorio y digestivo, normalmente estas bacterias se encuentran en cuerpos de agua naturales, tuberías y redes de distribución de agua y es resistente a la cloración del agua para consumo. Otro organismo emergente es Aeromonas hydrophyla, un patógeno oportunista que habita aguas naturales comúnmente aislado en la comida y el agua de consumo; esta bacteria se ha señalado como un agente potencial de gastroenteritis, septicemia, meningitis e infecciones en heridas, tanto en poblaciones inmunocomprometidas como en niños sanos. Otra bacteria patógena que puede ser aislada de cuerpos de agua es Helicobacter pylori, la cual se ha implicando en la enfermedad ácido péptica, ulceras gástricas y carcinoma gástrico.

\subsection{Vertido de antibióticos a cuerpos de agua como un origen de la cepas multiresistentes}

Las bacterias tienen alrededor de 3600 millones de años habitando este planeta, y los mecanismos evolutivos con los que cuentan son muy variados, lo que ocasiona que rápidamente puedan generar resistencia a los antibióticos. 
A diferencia de las eucariotas (células nucleadas presentes desde las plantas hasta los hepatocitos humanos) que usan el sexo, específicamente en el entrecruzamiento cromosómico en la meiosis gametogénica, como principal fuente de variación genética, las bacterias pueden usar otros recursos como las mutaciones puntuales, la recombinación genética y la transferencia horizontal de material genético entre especies e incluso entre géneros bacterianos distintos (Hernández, 2010). Esta amplia variedad de mecanismos evolutivos han permitido a las bacterias generar resistencia a antibióticos y "compartir" estas características entre ellas, a su vez, se ha demostrado que la capacidad infecciosa o virulenta de las bacterias también puede ser adquirida a través de estos mecanismos (MeléndezMarmolejo et al., 2020).

Para México, Rodríguez-Noriega et al. (2014) generan una revisión de los casos reportados de resistencia bacteriana en el periodo de 1973-2013. Inician con 1973 que es el año donde se produce una epidemia de salmonelosis resistente al cloranfenicol, tetraciclina, streptomicina y a las sulfas. Asimismo encuentran reportes de $E$. coli enterotóxica con resistencia a ampicilina, tetraciclina, estreptomicina y kanamicina. Otros organismos de importancia clínica compilados en la revisión de Rodríguez-Noriega et al. (2010), son Klebsiella pneumoniae, K. oxytoca, Serratia marcescens, Enterobacter cloacae, Pseudomonas aeruginosa, Acinetobacter baumannii, Streptoccocus pneumoniae, S. pyrogenes y Staphylococcus aureus.

Si bien el estudio mostrado por Rodriguez-Noriega et al. (2014), arroja resultados principalmente recabados de manera intrahospitalaria, trabajos como el de Tzoc et al. (2004) discuten la entrada de antibióticos a las descargas de aguas residuales desde los hospitales, además se ha observado que prácticas veterinarias y agrícolas también contribuyen con grandes cantidades de sustancias antibióticas al ambiente usando al agua como medio de transporte. Otros trabajos que analizan cuerpos de agua como los de López et al. (2009) sobre aguas de un río y el de Andersen y Sandaa (1999) sobre sedimentos marinos contaminados, reportan bacterias resistentes a distintos antibióticos, por mencionar algunos reportes

\subsection{Protozoos trasmitidos por el agua.}

Dentro de las eucariotas unicelulares que integran un conjunto variado de reinos distintos, destacan por su patogenia los protozoarios. Al igual que las bacterias estos organismos forman parte natural del microbioma en el tracto digestivo. Sin embargo, hay procesos o condiciones que les confieren características patogénicas. Algunos de los protozoarios que podemos encontrar en el intestino como comensales son especies del género Entamoeba, Endolimax y las Trichomonas, mientras que especies como E. histolytica, Iodomoeba buestchlii, Dientamoeba fragilis, Giardia intestinalis, Toxoplasma gondii y Balantium coli se consideran protozoarios patógenos (Solarte, 2006; Efstratiou et al., 2017).

En la actualidad los protozooarios causan más de 2.2 millones de muertes en todo el mundo, siendo los países tropicales los más afectados, y son la segunda causa de muerte entre menores de 5 años (Efstratiou et al., 2017). Asimismo, estos patógenos se encuentra tanto en países desarrollados como en aquellos en vías de desarrollo (Efstratiou et al., 2017; Rosado-García et al., 2017). Sin embargo, en países como los latinoamericanos, se desconoce la epidemiología de muchas de estas enfermedades (RosadoGarcía et al., 2017)

\subsection{Giardia sp}

La especie patogénica Giardia duodenalis (también llamadas G. intestinalis o G. lamblia), es un protozoario parásito unicelular no invasivo que infecta la parte superior del tracto intestinal de humanos y algunos animales (Cacciò et al., 2017). El patógeno puede llegar a los cuerpos de agua a través de la deposición de heces fecales humanas o de animales. Este microorganismo causa la enfermedad llamada giardiasis, y se manifiesta de manera sintomática en forma de diarrea, cólicos, dolor de cabeza, deshidratación y pérdida de masa corporal, aunque muchas veces es asintomática o el cuadro diarreico se resuelve solo (Koehler et al., 2013). Sin embargo, los niños, los ancianos y las personas inmunocomprometidas son las más afectadas y necesitan seguimiento médico más cercano (Einarsson $e t$ al., 2016; Cacciò et al., 2017). 


\subsection{Entamoeba y otras amibas}

La amibiasis es una enfermedad infecciosa ocasionada por la invasión de la mucosa del intestino grueso por amibas de las especies Entamoeba histolytica, E. dispar, E. hartmanni, E. coli, E. moshkovskii, E. polecki, Endolimax nana y Dientamoeba fragilis (Shimokawa et al., 2012). Siendo E. histolytica la reportada como patogénica en México (Caballero-Salcedo et al., 1994; Ximénez et al., 2007). No todas las cepas de E. histolytica tienen la capacidad genética para poder producir enfermedad y habitan el intestino de manera comensalista. Sin embargo, las cepas invasoras pueden dañar el tejido y desplazarse a distintas partes del hospedero, como el cerebro, hígado y pulmones. Recientemente se ha reportado que otra especie, E. moshvoskii puede causar patogenia en niños, desafortunadamente para México se desconoce la prevalencia o existencia de esta especie en la población (Shimokawa et al., 2012). Afortunadamente, en ambos casos estos padecimientos son prevenibles y tratables.

La ameba E. histolytica tiene una distribución mundial, y se adquiere a través de alimentos o bebidas contaminadas con quistes de la ameba. Los focos rojos de infección están distribuidos hacia regiones en vías de desarrollo como Latinoamérica, Asia y África (Shimokawa et al., 2012). En estas regiones existe una marcada sectorización de la infección en la población con relación a características sociodemográficas y accesibilidad a servicios sanitarios, como agua potable y pavimentación (Ximénez et al., 2007).

\subsection{Toxoplasma gondii}

Este protozoario es un microorganismo unicelular, obligado a vivir dentro de distintos tipos de células del ser humano y otros animales, causando toxoplasmosis. La forma de infectarse de $T$. gondii es mediante la ingestión de células de resistencia (oocystos) en comida o bebidas contaminadas con heces (Dubey y Jones, 2008). Aunque las formas de transmisión del parásito no solo se restringe a esta, pues incluso la transmisión puede darse de la madre al hijo durante la gestación (Dubey, 2009). Cuando una persona con un sistema inmunológico no comprometido se infecta generalmente no presenta síntomas pero, si los hay, se manifiestan algunos similares a la mononucleosis o una infección en la retina (Kochanowsky y Koshy, 2018). En personas inmunocomprometidas, este microorganismo puede a travesar la barrera hematoencefálica y provocar desordenes neurológicos al infectar tanto neuronas como células gliales (Kochanowsky y Koshy, 2018; Liu et al., 2017). Actualmente, T. gondii, está cobrando importancia ya que se ha postulado desde algunos estudios que este parásito tiene relación con el desarrollo de esquizofrenia y otras enfermedades neurológicas, aunque los resultados aun no son concluyentes (Esshili et al., 2016; Kochanowsky y Koshy, 2018).

\subsection{Crystosporidium sp.}

El estudio de este microorganismo tuvo gran auge a principios de la década de 1970 como clínicamente relevante, pues dentro de las personas afectadas destacaban niños y personas infectadas con el virus de la inmunodeficiencia humana (VIH). Desafortunadamente, la criptosporidiosis ha reemergido como un patógeno oportunista de vida libre y afecta principalmente a niños en países en vías de desarrollo, principalmente africanos y latinoamericanos (Clode et al., 2015; Mmbaga y Houpt, 2017). Del género se han descrito aproximadamente 40 genotipos, pero en humanos, $C$. hominis y $C$. parvum, son las especies que causan el $90 \%$ de los casos que se registran (Certad et al., 2017). La vía de transmisión del patógeno es fecal-oral, más que la vía zoonótica o persona-persona. Aquí el agua funge como un transporte efectivo para huevos o oocystos (células de resistencia) del patógeno, además de que se ha observado que puede formar biopelículas en superficies húmedas o sumergidas, las cuales son un reservorio del patógeno (Thompson et al., 2016).

Las manifestaciones clínicas de la infección por Cryptosporidium sp. ocurren pocos días después de que el hongo entra al tracto digestivo, aproximadamente de 2-14 días, produciendo diarrea acuosa, dolor abdominal, nauseas, vómito, perdida de talla y fiebre de bajo grado. Sin embargo, este panorama puede complicarse en personas inmunológicamente comprometidas o en niños desnutridos. En este tipo de pacientes la infección puede colonizar más allá del tracto digestivo y afectar al hígado y al páncreas, complicando el pronóstico y cuando la diarrea es severa el pronóstico se asocia a una mortalidad significativa (Certad et al., 2017). 


\subsection{Enfermedades no infecciosas relacionadas al agua}

Otros agentes disueltos en el agua que representan una amenaza para la salud son ciertos iones metálicos y compuestos químicos naturales o sintéticos, que pueden causar desequilibrios nerviosos, hormonales, renales, y diversos tipos de cáncer, que pueden llevar a la incapacidad, malformaciones embrionarias e incluso la muerte. Algunos de estos metales son el arsénico, cadmio, plomo y mercurio. Se sabe que la exposición a estas sustancias puede tener una causa natural como cuando se erosionan suelos ricos en metales pesados y el agua de la lluvia los arrastra. Sin embargo, las actividades industriales, mineras y petroleras pueden verter entre sus desechos estos metales al ambiente. La forma en que llegan estos metales a las personas es por el riego de vegetales con aguas contaminadas y posteriormente estos son consumidos, también por bioacumulación y movilidad en el ambiente estos metales pueden encontrarse en peces, carnes y leche (Reyes et al., 2016).

El arsénico está considerada por la Agencia de Protección Ambiental (EPA) como un carcinogénico, encontrándose en disuelto en el agua o depositado en suelos. La exposición continua a arsénico ha sido ligada a desequilibrios cardiovasculares, diabetes, cáncer de pulmón, anemia, neuropatía periférica, irritación de la piel y las mucosas y daño en el hígado y riñones (Lyn, 2003).

Se considera al cadmio como una de las sustancias más tóxicas encontradas en el ambiente, a este llega de manera natural o artificial, producto de fertilizantes o de un deficiente proceso de tratamiento de las aguas residuales (Waalkes, 2003). Cuando el cadmio es absorbido por una persona primero se une a los eritrocitos o a la albumina plasmática y posteriormente se acumula en huesos, hígado, páncreas, riñones y la placenta, causando desórdenes en la función deseos órganos y teratogénesis en el feto (Lyn, 2003; Liu, 2009).

\subsection{Contaminantes emergentes en el agua.}

Conforme cambian las rutinas, los hábitos, las tendencias de consumo y alimentación y las propias tecnologías que hacen posible tales actividades, nuevas sustancias de origen sintético o natural son introducidas al ambiente (Daughton, 2004). Los contaminantes emergentes por definición son un conjunto de sustancias no reguladas que se encuentran en el ambiente en cantidades extremadamente bajas, además de que se requieren análisis especiales para evidenciar su existencia. A su vez, se sabe que la principal puerta de entrada al ambiente de estas sustancias es por vías como aguas residuales domésticas, industriales o infiltración de actividades agrícolas (Gil et al., 2012).

Desafortunadamente muchas de estas sustancias tienen consecuencias catastróficas en los sistemas biológicos, pueden bioacumularse, tener efectos miméticos con sustancias naturalmente presentes como algunas hormonas y provocar un efecto de disruptor endócrino en órganos blancos, además se ha demostrado que algunas de estas puede influir en la aparición de distintos tipos de cánceres. También, en ocasiones, el proceso de degradación de estas sustancias crea metabolitos más tóxicos que en original (Becerril, 2009).

Muchas de estas sustancias no se encuentran reguladas en la mayoría de los países, y se liberan al medio indiscriminadamente, sin conocer los posibles efectos que estos tendrán sobre la salud. Algunos de estos llamados contaminantes emergentes provienen como productos de la potabilización de agua, pesticidas usados en la agricultura, surfactantes, drogas ilícitas, los lodos de las plantas de tratamiento del agua, fármacos, incineración o degradación en el tiempo de residuos sólidos, productos de uso personal, y en general sustancias usadas en procesos industriales (Becerril, 2009; Gil et al., 2012; Jiménez, 2011).

\subsection{Normatividad mexicana sobre el agua para consumo}

Un factor importante para la salud de la población es la provisión de agua potable y de saneamiento pues evita su exposición a los agentes patógenos. El adecuado y oportuno acceso a estos servicios reduce la mortalidad y morbilidad entre la población, en especial la menor de cinco años, disminuye las enfermedades de transmisión hídrica (hepatitis viral, fiebre tifoidea, cólera, disentería y otras causantes de diarrea) y los trastornos resultantes del consumo de componentes químicos patógénicos (arsénico, nitratos o flúor). 
Dentro del marco jurídico vigente hay varios ordenamientos con disposiciones en materia de agua. La Constitución Política de los Estados Unidos Mexicanos (CPEUM), en su artículo 4, párrafo quinto, habla de que: "Toda persona tiene derecho a un medio ambiente adecuado para su desarrollo y bienestar...", el agua es un recurso natural que forma parte de nuestro ambiente, por lo que ahí, indirectamente, se estatuye el derecho al agua. El artículo 115 especifica que los municipios tienen a su cargo los servicios públicos de agua potable, drenaje, alcantarillado, tratamiento y disposición de sus aguas residuales.

El agua es un tema transversal que abarca diferentes esferas tales como medio ambiente, salud, saneamiento, entre otras; y así se refleja en la normatividad mexicana. Existen diversas normas aplicables al tema del agua algunas de las normas más relevantes se pueden aglomerar por grupos: SEMARNAT (Secretaría de Medio Ambiente y Recursos Naturales), Comisión Nacional del Agua (CONAGUA), salud, energía y normas mexicanas. Se debe enfatizar que, conforme a la Ley Federal sobre Metrología y Normalización, las Normas Oficiales Mexicanas (NOM), son regulaciones técnicas de observancia obligatoria, en tanto que las Normas Mexicanas (NMX) son de aplicación voluntaria. Se hará referencia a aquellas cuya observancia está directamente vinculada con lo descrito es este capítulo.

Dentro del grupo SEMARNAT destacan la NOM-001-SEMARNAT-1996 que estableció fechas de cumplimiento para sus requerimientos de límites máximos permisibles en las descargas de aguas residuales en aguas y bienes nacionales; y la NOM-003-SEMARNAT-1997 que establece los límites máximos permisibles de contaminantes para las aguas residuales tratadas que se reúsen en servicios al público.

CONAGUA es el organismo administrativo desconcentrado de la SEMARNAT, creado para administrar y preservar las aguas nacionales y sus bienes inherentes, para lograr su uso sustentable, con la corresponsabilidad de los tres órdenes de gobierno y la sociedad en general. Ha expedido normas que establecen las disposiciones, especificaciones y métodos de prueba que permiten garantizar que los productos y servicios asociados al sector hídrico cumplan de manera eficiente, preservando el agua en cantidad y calidad. Existen un total de 10 normas vigentes en materia del cuidado, transporte y tratamiento del agua, casi una norma por cada proceso.

La NOM-001-CONAGUA-2011 establece todos los parámetros para que llegue el agua a los hogares, de las tomas domiciliares, las especificaciones de los tubos por donde llega, así como de las alcantarillas por donde se desecha; asegura el cumplimiento de los estándares de hermeticidad y durabilidad de los productos empleados para estos procesos. Los requisitos para la construcción de pozos de extracción y cuidado de acuífero se acotan, en las NOM-003-CONAGUA-1996 y NOM-004CONAGUA-1996. Las especificaciones y métodos de prueba para fosas sépticas prefabricadas las dicta la NOM-006-CONAGUA-1997. De hecho a todas las piezas de las tazas de baño se les aplica la normatividad: NOM-009-CONAGUA-2001 específicamente para inodoros; NOM-010-CONAGUA2000 para las válvulas de los tanques de los inodoros y la NOM-008- CONAGUA-1998, enfocada en las regaderas para aseo corporal.

La NOM-011-CONAGUA-2000 es una norma a destacar, ya que en ella se fundamenta el cálculo de la disponibilidad de agua en cuencas y acuíferos. Por último existen las: NOM-014-CONAGUA-2003 y NOM-015-CONAGUA-2007 orientadas a la infiltración artificial de agua a los acuíferos.

En el título sobre promoción de la salud, la Ley General de Salud de 1984, faculta a la Secretaría de Salud (SSA) para determinar los valores de la concentración máxima permisible para el ser humano de contaminantes en el ambiente, emitir las normas técnicas a que deberá sujetarse el tratamiento de agua para uso y consumo humano, y establecer los criterios sanitarios para el uso, tratamiento y disposición de aguas residuales, además incluye las sanciones a quien contamine cualquier cuerpo de agua, con el fin de evitar riesgos y daños a la salud pública. Y establece que la SSA es la responsable de fijar los requisitos sanitarios para el consumo humano; para ello las NOM definen los parámetros, que incluyen características físicas (profundidad, temperatura), biológicas (bacterias y parásitos) y químicas; de tipo orgánico, inorgánico (sales, metales, plaguicidas) y en trihalometanos (compuestos que se forman de la reacción de la materia orgánica con derivados halogenados). 
Son siete normas dentro de las cuales sobresalen tres: NOM-179-SSAI-1998 (calidad del agua para consumo humano en sistemas de abastecimiento público), para la vigilancia y evaluación del control de calidad del agua para uso y consumo humano, distribuida mediante sistemas de abastecimiento público; y la NOM-230-SSAI-2002 (requisitos sanitarios de los sistemas de abastecimiento y procedimientos sanitarios para el muestreo químico, físico y microbiológico e incluso radioactivo), que contiene los requisitos sanitarios que se deben cumplir en los sistemas de abastecimiento públicos y privados durante el manejo del agua, así como los procedimientos sanitarios para el muestreo de sitios donde se monitorea la cloración. Por su parte, la NOM-127-SSA1-1994 establece los lineamientos para garantizar el abastecimiento de agua para uso y consumo humano con calidad adecuada. Esta norma establece límites permisibles de características bacteriológicas (coliformes fecales y coliformes totales); de características físicas y organolépticas (color, olor, sabor y turbiedad); de características químicas (comprende 34 parámetros, tales como aluminio, arsénico, bario, entre otros), así como los métodos de tratamiento que se deben aplicar según los contaminantes encontrados. En nuestro país, los prestadores del servicio de agua potable, generalmente los municipios, llevan a cabo la desinfección del agua mediante cloración, condición necesaria para destruir o inactivar agentes patógenos o parásitos microscópicos, conforme a esta norma. El procedimiento de desinfección del agua se evalúa por la determinación de cloro libre residual en la toma domiciliaria.

De acuerdo con fuentes oficiales en México, los problemas de calidad de agua son fuertes y tienen un grande rezago en su atención, comparados con los relativos a la cantidad y a la provisión de servicios a la población, por ello, el monitoreo de la calidad del agua es un proceso que debe ser eficaz, regulado y actualizado (Carabias, 2005). En este sentido, interesa destacar la importancia de los acuíferos (aguas subterráneas), pues en México aportan cerca de $58.6 \%$ del uso agrupado abastecimiento público (Conagua, 2016). Su potabilidad se establece legalmente cuando un acuífero cumple con los parámetros estipulados en la norma NOM-127-SSA1-1994. Los estudios sobre su calidad, al igual que los programas de protección son pocos, particularmente los relacionados con su calidad fisicoquímica, se le da seguimiento adecuado a ciertos factores contaminantes como indicadores de contaminación (demanda química y bioquímica de oxígeno y sólidos suspendidos). Se considera que el problema de la contaminación de acuíferos es preocupante en el país, con estimaciones superiores a 90 por ciento y más de los cuerpos de agua (Jiménez, 2008; Aboites et al. 2008). la calidad del agua subterránea se deteriora por sobreexplotación, y en las últimas décadas el número de acuíferos sobreexplotados se triplicó; de 32, en 1975, a 105, en 2015 (Aboites et al. 2008, Conagua, 2016).

En cuanto a su calidad bacteriológica, aunque han aumentado las localidades que realizan la desinfección del agua por cloración y el número de plantas potabilizadoras en el país (874 en 2015 de acuerdo a Conagua, 2016), permanecen diferencias notables entre la eficiencia de cloración y su monitoreo, sobre todo cuando se compara su desempeño entre entidades federativas, y entre las localidades de los estados.

Si se usa el agua subterránea como fuente de abastecimiento de agua potable, entre las sustancias tóxicas que puede contener, una de las más preocupantes es el arsénico. La concentración máxima de arsénico en el agua potable establecida por la normatividad mexicana es de 0.05 mg/l (NOM-127-SSA11994) cantidad que se fija tomando en cuenta las propiedades cancerígenas, tóxicas y organolépticas del elemento, así como los efectos que pueda causar a los organismos presentes en los cuerpos de agua. Sin embargo, en los últimos años, debido al conocimiento de los efectos en la salud por ingerir agua con altos contenidos de arsénico, la OMS recomendó en una concentración máxima permisible de $0.01 \mathrm{mg} / \mathrm{l}$. Esta recomendación se basa en estudios epidemiológicos realizados en diferentes países (China, Taiwan, India, Japón, Chile y Argentina) en los cuales se encontró relación entre el cáncer de piel y la cantidad de arsénico y el agua de beber. En Estados Unidos, actualmente el límite máximo para arsénico es de $0.05 \mathrm{mg} / \mathrm{l}$, pero se ha iniciado una seria revisión de los límites máximos permisibles, con la finalidad de evaluar la recomendación de la Organización Mundial de la Salud (Alarcón et al. 2015).

\subsection{Cambio climático, salud y agua}

Aunque algunos gobiernos aun lo niegan, entre la comunidad científica es ampliamente aceptado que la acumulación de gases de efecto invernadero en la atmosfera ha desequilibrado el clima global y las temperaturas están en aumento. 
La organización mundial de la salud señala que producto de cambio climático aproximadamente 150,000 personas mueren anualmente en el mundo, derivado de desnutrición, infecciones, enfermedades cardiovasculares y respiratorias (Patz et al., 2005; Barrett et al., 2015).

Se ha documentado que cambios en la temperatura y temporadas de lluvia pueden afectar la distribución de vectores como aquellos de la malaria y el dengue, y también aumentar la incidencia de enfermedades diarreicas (Haines et al., 2006; Patz y Holson, 2006; Shuman, 2010). De la misma manera, para aquellos lugares donde el cambio climático ha traído consigo disminución en la lluvia como en la amazona y en Centroamérica patógenos como la malaria probablemente disminuyan su transmisión (Haines et al., 2006). En el caso del dengue cuyo vector Aedes aegypti se cree que puede expandirse hasta áreas más templadas y provocar brotes del virus entre la población (Hales et al., 2002). Es decir, la alta concentración de patógenos hacia los trópicos se debe a su vez a la presencia múltiples vectores, así si las temperaturas cambian estos vectores pueden migrar hacia otras zonas, incluso a miles de kilómetros de sus centros de origen (Lafferty, 2009). Otro efecto que trae consigo el cambio climático es la intensificación de las tormentas, y producto de ello se ha observado que en algunos casos, han producido la movilización de químicos peligrosos como los pesticidas y metales pesados a los cuerpos de agua (Haines et al., 2006).

El Niño es uno de los fenómenos climáticos que más se han intensificado con el cambio climático. Y es durante las últimas décadas que los periodos del fenómeno donde la temperatura aumenta drásticamente se han dado las condiciones para que patógenos que se transmiten por agua, como el hantavirus o la bacteria causante del cólera, proliferen (Patz et al., 2005; Shuman 2010). Otros patógenos que se cree han proliferado junto con el cambio climático son Mycobacterium avium, Helicobacter pylori y Aeromonas hydrophyla (O’Dwyer et al., 2016).

\subsection{Referencias}

Aboites, L., E. Cifuentes, B. Jiménez y M. L. Torregrosa. (2008). Agenda del agua. Pendientes nacionales del agua. México: Academia Mexicana de Ciencias. http://cisnex.amc.edu.mx/amc/agenda_del_agua.pdf (13 de marzo de 2009).

Alarcón Herrera, M. T. , Montenegro, I. F., Navar, P. R., Domínguez, I. R. M., \& Vázquez, R. T. (2015). Contenido de arsénico en el agua potable del valle del Guadiana, México. Tecnología y Ciencias del Agua, 16(4), 63-70.

Andersen, Sigrid y Sandaa, Ruth (1999). "Distribution of tetracycline resistance determinants among Gram-negative bacteria isolated from polluted and unpolluted marine sediments". Applied and environmental microbiology, 60(3), 908-913.

Andrades, Patricio, Sepúlveda, Sergio y González, Josefina (2004). "Curación avanzada de heridas". Revista Chilena de Cirugía, 56(4), 396-403.

Arreguín-Moreno, Rocío Haydee, Román-Pérez, Rosario, Laborin-Álvarez, Jesús Fancisco, Moreno, José Luis, Valdez, Elba Abril y Valenzuela, Blanca (2009). "Factores psicosociales relacionados con el consumo doméstico de agua en una región remidesértica". Salud Pública de México, 51(4), 321-326.

Barrett, Bruce, Charles, Joel y Temte, Jonathan (2015). "Climate change , human health, and epidemiological transition". Preventive Medicine, 70, 69-75.

Becerril, J.E. y Jiménez, B. (2007). "Potable water and sanititation in Tenochtitlan: Aztec culture". Water Science \& Technology: Water Supply, 7(1), 147-154.

Becerril, José (2009). “Contaminantes Emergentes en el Agua”. Revista Digital Universitaria, 10(8), 2 7.

Bruguera, Miguel (2006). "Prevención de las hepatitis virales". Revista de Enfermedades Infecciosas y Microbiología Clínica, 24(10), 649-656.

Caballero-Salcedo, A., Viveros-Rogel, M., Salvatierra, B., Tapia-Conyer, R., Sepúlveda-Amor, J. y 
Gutiérrez, G. (1994). "Seroepidemiology of amebiasis in México". The American journal of tropical medicine and higiene, 50, 412-419.

Cabral, Joao (2010). "Water Microbiology.Bacterial Pathogens and Water". International Journal of Enviromental Research and Public Health, 7, 3657-3703.

Caccio, Simone, Lalle, Marco y Svärd, Staffan (2017). "Host specificity in the Giardia guodenalis species complex". Infection, Genetics and Evolution.

Carabias, J. 2005. Agua, medio ambiente y sociedad. México: El Colegio de México (colmex), Fundación Gonzalo Río Arronte, unam

Carriedo, Angela, Bonvecchio, Anabelle, López, Nancy, Morales, Maricruz, Mena, Carmen, Théodore, Florence y Irizarry, Laura. (2013). "Uso del mercadeo social para aumentar el consumo de agua en escolares de la Ciudad de México". Salud Pública de México, 55(3), 388-396.

Certad, Gabriela, Viscogliosi, Eric, Chabé y Caccio, Simone (2017). "Pathogenic mechanisms of Cryptosporidium and Giardia”. Trends in Parasitology, 33(7), 561-576.

Clode, Peta, Koh, Wan y Thompson, Andrew (2015). "Life without a Host Cell: What is Cryptosporidium". Trends in Parasitology, 31(12), 614-624.

Comisión Nacional del Agua (Conagua). (2016). Estadísticas del agua en México, edición 2016. Secretaría del Medio Ambiente y Recursos Naturales, Comisión Nacional del Agua. México

Daughton, Christian (2004). Non-Regulated water contaminants: emerging research. Enviromental Impact Assessment Review, 24, 711-732.

Dubey, J.P. (2009). "History of the discovery of the life cycle of Toxoplasma gondii". International Journal for Parasitology, 39, 877-882.

Dubey, J.P. y Jones, J.L. (2008). "Toxoplasma gondii infection in humans and animals in the United States". International Journal for Parasitology, 38, 1257-1278.

Efstratiou, Artemis, Ongerth, Jerry y Karanis, Panagiotis (2017). "Waterborne transmission of protozoan parasites: Review of worldwide outbreaks- An update 2011-2016”. Water Research, 114, 14-22.

Einarsson, Elin, Ma'ayeh, Showgy y Svärd, Staffan (2016). “An up-date on Giardia and giardiasis”. Current Opinion in Microbiology, 34, 47-52

Elder, John P., Holub, Christina K., Arredondo, Elva M., Sánchez-Romero, Luz María, Moreno-Saracho, Jessica E., Barquera, Simón y Rivera, Juan (2014). "Promotion of wáter cosumption in elementary school children in San Diego, USA and Tlaltizapan, Mexico". Salud Pública de México, 56(2), 148-156.

Espinosa-Montero, Juan.; Aguilar-Tamayo, Manuel Francisco; Monterrubio-Flores, Eric Alejandro y Barquera-Cervera, Simón (2013). "Conocimiento sobre el consumo de agua simple en adultos de nivel socioeconómico bajo de la ciudad de Cuernavaca, México". Salud Pública de México, 55(3), 423-430.

Esshili, Awatef, Tabet, Sihem, Jemli, Achraf, Trifa, Fatma, Mechri, Anouar, Zaafrane, Ferid, Gaha, Lotfi, Juckel, Georg, Babba, Hamouda y Hadj, Besma (2016). "Toxoplasma gondii infection in schizophrenia and associated clinical features". Psychiatry Research, 245, 327-332.

Gil, Miriam, Soto, Adriana, Usma, Jorge y Gutiérrez, Omar (2012). "Contaminantes emergentes en aguas, efectos y posibles tratamientos”. Producción + Limpia, 7(2), 52-73.

González, Laura, Casanova, María, Pérez, Joaquín (2011). "Cólera: historia y actualidad". Revista de Ciencias Médicas, 15(4), 280-294. 
Haines, A., Kovats, R.S, Campbell, D. y Corvalan, C. (2006). "Climate change and human health: Impacts, vulnerability and public health". Public health, 120, 585-596.

Hales, Simon, de Wet, Neil, Maindonald, John y Woodward, Alistair (2002). "Potential effect of population and climate changes on global distribution of dengue fever: an empirical model". Lancet, 360, 830-834.

Haro, J. A., Nubes, G., y Calderón Ortiz, J. R. (2012). Riesgos sanitarios en calidad bacteriológica del agua: Una evaluación en diez estados de la república mexicana. Región y sociedad, 24(SPE3), 257-288.

Jiménez, B., Mazari, M., Domínguez, R., y Cifuentes, E. (2004). El agua en el Valle de México. El agua en México vista desde la academia. Science Academy, Mexico.

Jiménez, Claudio (2011). "Contaminantes orgánicos emergentes en el ambiente: Productos farmacéuticos”. Revista Lasallista de Investigación, 8(2), 143-153.

Jiménez-Corona, Aída, Gutiérrez-Cogio, Lucina, López-Moreno, Sergio y Tapia-Conyer, Roberto (1995). "El Cólera en México. Situación epidemiológica actual". Gaceta Médica Mexicana, 131(3), 363366

Kochanowsky, Joshua y Koshy, Anita (2018). “Toxoplasma Gondii”. Current Biology, 28, 770-771.

Koehler, Anson, Jex, Aaron, Haydon, Shane, Stevens, Melita, Gasser, Robin (2014).

"Giardia/Giardiasis- A perspective on diagnostic and analytical tools". Biotechnology advances, 32, 280289.

Lafferty, Kevin (2009). "The ecology of climate change and infectious diseases”. Ecology, 90(4), 888900

Lauria, Jim (2008). "Water filtration:Using water treatment to tackle the environmental footprint issue". Filtration \& Separation, 45(10), 20-23

Leclerc, H., Schawartzbrod, L. y Dei-Cas, E. (2002). "Microbial Agents Associated with Waterborne Diseases". Critical Reviews in Microbiology, 28(4), 371-409.

Liu, Jie, Qu, Wei, Kadiiska, Maria (2009). "Role of oxidative stress in cadmium toxicity and carcinogenesis". Toxicology and Applied Pharmacology, 238, 209-214.

Liu, Lei, Liu, Li-Na, Wans, Peng, Lv, Tian-Tian, Fan, Yin-Guang y Pan, Hai-Feng (2017). "Elevated seroprevalence of Toxoplasma gondii in AIDS/HIV patients: A meta-analysis". Acta Tropica, 176, 162167.

Llorente Nostl, Natalia y Casas Osorio, Sara (2007). Agua y Salud. España: Ideasamares.

López, Osvaldo, León, Josefina, Jiménez, Maribel y Chaidez, Cristobal (2009). "Detección y resistencia a antibióticos de Escherichia coli y Salmonella en agua y suelo agrícola". Revista de Fitotécnica Mexicana, 32(2), 119-126.

Lynn, Patrick (2003). "Toxic Metals and Antioxidants: Part 1l. Role of Antioxidants in Arsenic and Cadmium Toxicity”. Alternative Medicine Review, 8(2), 106-128.

Meléndez-Marmolejo, J., García-Saavedra, Y., Galván-Romero, V., de León-Martínez, L. D., VargasBerrones, K., Mejía-Saavedra, J., \& Ramírez, R. F. (2020). "Contaminantes emergentes. Problemática ambiental asociada al uso de antibióticos. Nuevas técnicas de detección, remediación y perspectivas de legislación en América Latina". Revista de Salud Ambiental, 20(1), 53-61.

Martinez, Bernardo (1992). "El cólera en México durante el siglo XIX". CIENCIAS, 25, 37-40. Mays, Larry (2013). "A brief history of water filtration/sedimentation". Water Science \& Technology: Water Supply, 13(3), 735-742. 
Mmbaga, Blandina y Houpt, Eric (2017). "Cryptosporidium and Giardia infections in Children: A Review”. Pediatric Clinics of North America, 64(4), 837-850.

Mussaret, Zaidi, López, Constantino y Calva, Edmundo (2006). "Estudios mexicanos sobre Salmonella: epidemiolgía, vacunas y biología molecular”. Revista Latinoamericana de Microbiología, 48(2), 121125.

O'Dwyer, Jean, Dowling, Aideen y Adley, Catherine (2016). "The impact of Climate Change on the Incidence of Infectious Waterborne Disease". En: Eslamian, Saeid (Ed.). The Urban Water Reuse Handbook, Estados Unidos de America: CRC Press, 1017-1026

Patz, Jonathan y Olson, Sarah (2006)."Malaria risk and temperature: Influences from global climate change and local land use practices". Proceedings of the Natonal Academy of Sciences, 103(15), 56355636.

Patz, Jonathan, Campbell, Diarmid, Holloway, Tracey y Foley, Jonathan (2005). "Impact of regional climate change on human health". Nature Reviews, 438, 310-317.

Preethi, V. B., Sheeba, Ganesan; Pazhni, G.P; Ramamurthy, T.; Nair, G.B y Ventakatasubramanian, Padma (2012). "Storing Drinking-water in Copper pots kills Contaminating Diarrhoegenic Bacteria". Journal of Health, Population and Nutrition, 30(1), 17-21.

Reyes, Yulieth, Vergara, Inés, Torres, Omar, Díaz, Mercedes y González, Edgar (2016). Contaminación por metales pesados: implicaciones en salud ambiente y seguridad alimentaria. Revista de Ingeniería, Investigación y Desarrollo, 16(2), 66-77.

Rezende, Guilhermo, Roque-Afonso, Anne Marie, Samuel, Didier, Gigou, Michele, Nicand, Elisabeth, Ferre, Virginie, Dussaix, Elisabeth, Bismuth, Henri y Féray, Cyrille (2003). Viral and Clinical Factors Associated With the Fulminant Course of Hepatitis A Infection. HEPATOLOGY, 38(3), 613-618

Rivera, Juan A., Muñoz-Hernández, Onofre, Rosas-Peralta, Martín, Aguilar-Salinas, Carlos A., Popkin, Barry M., Willett, Walter C. (2008). "Consumo de bebidas para una vida saludable: recomendaciones para la población mexicana". Salud Pública de México, 50(2), 173-195.

Rodríguez-Noriega, Eduardo, León-Garnica, Gerardo, Petersen-Morfín, Santiago, Pérez-Gómez, Hector, González-Díaz, Esteban y Morfín-Otero, Rayo (2014). "La evolución de la resistencia bacteriana en México, 1973-2013”. Revista Biomédica, 34(1), 181-190.

Rosado-Garcia, Félix, Guerro-Flórez, Milena, Karanis, Gabriele, Hinojosa, Maria y Karanis, Panagiotis (2017). "Water-borne protozoa parasites: The Latin America perspective". International Journal of Hygiene and Enviromental Health, 220, 783-798.

Scarborough, Vernon L. y Gallopin, Gary G. (1991). A water Storage Adaptation in the Maya Lowlands. Science, 251, 658-662.

Secretaría de Medio Ambiente y Recursos Naturales (Semarnat). (2016) Informe de la Situaciónisẹpidel Medio Ambiente en México. Compendio de Estadísticas Ambientales. Indicadores Clave, de Desempeño Ambiental y de Crecimiento Verde. Edición 2015. Semarnat. México.

Shimokawa, Chikako, Kabir, Mamun, Taniuchi, Mami, Mondal, Dinesh, Kobayashi, Seiki, Ali, Karim, Sobuz, Shihab (2012). "Entamoeba moshkovskii Is Associated With Diarrhea in Infants and Causes Diarrhea and Colitis in Mice". The Journal of Infectious Diseases, 206, 744-751

Shuman, Emily (2010). "Global climate Change and Infectious Diseases". The New England Journal of Medicine, 362(12), 1061-1063.

Solarte, Yezid, Peña, Miguel y Madera, Carlos (2006). "Transmisión de protozoarios patógenos a través del agua para consumo humano". Colombia Médica, 37(1), 74-82. 
Tanno, Hugo y Fay, Oscar (2005). "Hepatitis Viral en América Latina”. Acta Gastroenterológica Latinoamericana, 35(3), 169-182.

Thompson, Andrew, Koh, Wan y Clode, Peta (2016). "Cryptosporidium- What is it?". Food and Waterborne Parasitology, 2, 54-61.

Tovar,Victor y Bustamante, Patricia (2000). "Historia del cólera en el mundo y México". Ciencia Ergo Sum, 7(2), 178-184.

Tzoc, Eduardo, Arias, María y Valiente, Carmen (2004). "Efecto de las aguas residuales hospitalarias obre los patrones de resistencia a antibióticos de Escherichia coli y Aeromonas sp.". Revista Biomédica, $15,165-172$.

Valdespino, José Luis, Ruiz-Gómez, Juan, Olaíz-Fernández, Gustavo, Arias-Toledo, Eloisa, CondeGonzález, Carlos J., Palma, Oswaldo y Sepúlveda, Jaime (2007). "Seroepidemiología de la hepatitis A en México. Sensor de inequidad social e indicador de políticas de vacunación”. Salud Pública de México, 40(2), 377-385.

Waalkes, Michael (2003). "Cadmium Carcinogenesis". Mutation research, 533, 107-120.

Ximénez, Cecilia, Morán, Patricia, Ramos, Fernando, Ramiro, Manuel (2007). "Amibiasis intetinal: estado actual de conocimiento". Medicina Interna de México, 23(5), 398-407 